\title{
Getting there together: highlights, challenges and opportunities for tobacco control in the Oceania region
}

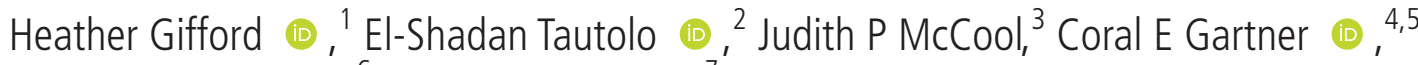 \\ Richard Edwards (1), ${ }^{6}$ Raglan Maddox (1) ${ }^{7}$
}

${ }^{1}$ Whakauae Research, Whakauae Research for Maori Health and Development, Whanganui, ManawatuWhanganui, New Zealand ${ }^{2}$ Centre for Pacific Health and Development, Auckland University of Technology, Auckland, New Zealand ${ }^{3}$ School of Population Health, University of Auckland, Auckland, New Zealand ${ }^{4}$ School of Public Health, University of Queensland, Herston, Queensland, Australia ${ }^{5}$ Queensland Alliance for Environmental Health Sciences, University of Queensland Faculty of Health and Behavioural Sciences, Woolloongabba, Queensland, Australia

${ }^{6}$ Department of Public Health, University of Otago, Wellington, New Zealand

${ }^{7}$ Aboriginal and Torres Strait Islander Health Program, National Centre for Epidemiology and Public Health, Australian National University, Acton, Australian Capital Territory, Australia

\section{Correspondence to}

Dr Heather Gifford, Whakauae Research, Whakauae Maori Health Research and Development, Wanganui 4500, Manawatu-Wanganui, New Zealand;

heather@whakauae.co.nz

Received 17 June 2021 Accepted 3 November 2021

\section{Check for updates}

(C) Author(s) (or their employer(s)) 2022. No commercial re-use. See rights and permissions. Published by BMJ.

To cite: Gifford H, Tautolo ES, McCool JP, et al.

Tob Control

2022;31:164-168

\section{ABSTRACT \\ Background The paper focuses on the geographical region of Oceania. We highlight the tobacco control leadership demonstrated in this region and describe the challenges and opportunities to achieving country- specific smoke-free goals.}

Results Significant achievements include smoke-free nation goals, world-leading initiatives such as plain packaging, and a bold plan by New Zealand to reduce the retail availability of smoked tobacco products and remove virtually all the nicotine from cigarettes and rolling tobacco. There are significant challenges and opportunities before reaching smoke-free status including implementation pathways requiring strong governance and leadership and compliance monitoring and enforcement.

Conclusions We conclude that achieving a smokefree Oceania is possible through already existing bold country and regional smoke-free goals, excellent tobacco control leadership, experience and resources, and an understanding of how to work collectively. However, a commitment to focus tobacco control efforts regionally is required to achieve a smoke-free Oceania together.

\section{CONTEXT FOR TOBACCO CONTROL IN OCEANIA}

Oceania includes Australasia (Australia and New Zealand), and 22 Pacific Island Countries and Territories (PICTs) across Melanesia, Micronesia, and Polynesia (figure 1). Most of Oceania's population of over 41 million live in Australia (25.4 million), Papua New Guinea (8.8 million) and New Zealand (4.9 million).

Although the Oceania region has been a leader in tobacco control policy, these gains have not been universal or equitable. The region has one of the highest burdens of preventable non-communicable disease (NCD), a significant proportion of which can be attributed to tobacco use. Examples of stellar success are offset by an active tobacco industry and glaring disparities across the region.

Oceania has been shaped by colonisers who settled and established governance over the Indigenous peoples. The PICTs, where the Indigenous peoples remain the majority population, have retained distinct economic, political and parliamentary systems. In Australia and New Zealand, nonIndigenous peoples (predominantly Europeans) became the majority and established political, economic, and cultural dominance. Colonisation disrupted social structures, community resources, and altered cultures, practices and values to differing degrees across Oceania. ${ }^{1}$ This included the introduction, commercialisation and trade of tobacco throughout the region; trading commercial tobacco as a profitable, but harmful commodity. ${ }^{2}$ Reducing the harm caused by the tobacco epidemic is reflected in biennial Oceania Tobacco Control Conferences which bring together tobacco control researchers, advocates, policymakers and administrators from across the region. This collaboration underpins the spirit of the WHO Framework Convention on Tobacco Control (FCTC) ${ }^{3}$ and acknowledges 'the high levels of smoking and other forms of tobacco consumption by Indigenous people'.

Australia and New Zealand have strong historical partnerships, and a major influence on PICTs. Objectives of Australian and New Zealand foreign policy with PICTs are primarily focused on trade and capital flows, migration and labour force needs and strategic considerations such as sovereignty, stability, security, and prosperity for the region. ${ }^{4}$ Both countries play a significant role in development assistance to the Pacific via bilateral and multilateral intermediaries. Significant numbers of Pacific Island peoples live in New Zealand ${ }^{6}$ and Australia ${ }^{7}$ facilitated through various constitutional acts (eg, Cook Islands Constitution Act 1964 and Niue 1972) which articulate rights to citizenship and through the Trans-Tasman Travel Arrangement. ${ }^{8}$

\section{Prevalence}

Smoking prevalence varies among PICTs from $17.7 \%$ in Niue to $62.4 \%$ in Federated States of Micronesia (FSM) (adults, both sexes) (table 1). Smoking prevalence was higher among male (range: $24.6 \%$ in Niue; $69.1 \%$ in FSM) than female (range: $4 \%$ in Vanuatu; 63\% in Tokelau) in all countries except Tokelau. Smoking prevalence in PICTs was mostly considerably higher than in Australia and New Zealand. The only notable exception was Niue, a New Zealand Realm ${ }^{9}$ country with a fluctuating population of around 1619 residents. It is tempting to attribute lower smoking prevalence in Niue to its 'free association' (Realm country status). However, Tokelau, also a Realm country, has among the highest smoking prevalence in the region.

Smoking prevalence in New Zealand and Australia has decreased at similar rates over the last three decades to around 11\%-13\% currently. ${ }^{10-12}$ Smoking rates among Indigenous populations and those living in the most deprived communities ${ }^{13}$ remain comparatively high. ${ }^{10-12}$ For instance, Māori women have the highest daily smoking prevalence 


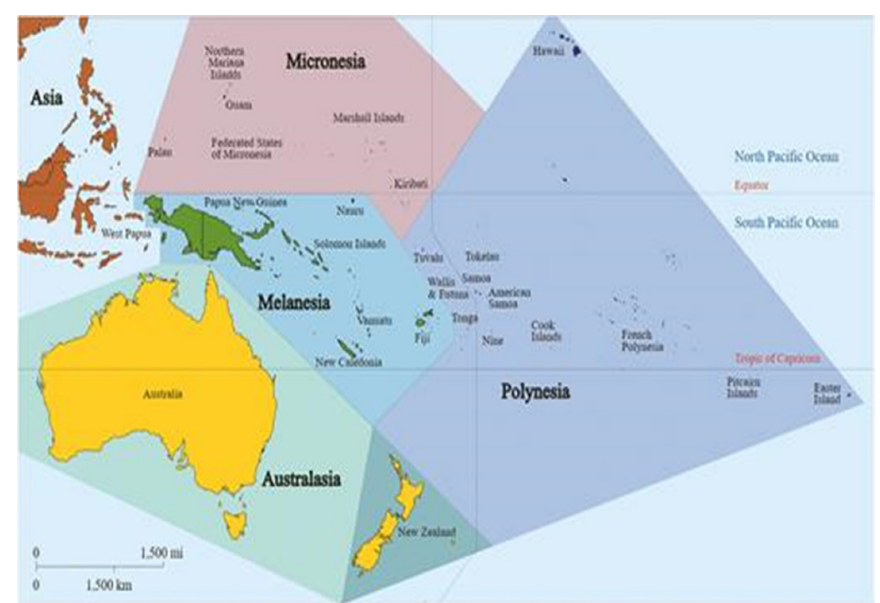

Figure 1 Map of Oceania region.

(33\%) in New Zealand. ${ }^{10}$ Smoking prevalence among Pacific peoples living in New Zealand remains persistently high, with only a small reduction in the last 10 years. ${ }^{10} 14$ People living in the most deprived areas are over five times more likely to smoke than those living in the least deprived areas. ${ }^{10} 14$ Similar patterns are evident in Australia. ${ }^{15}$ Despite significant declines in daily smoking prevalence among Aboriginal and Torres Strait Islander peoples, down to $40.2 \%$ in $2018 / 2019$ from $50.0 \%$ in $2004-$ 2005 , smoking remains much higher than in the non-Indigenous population and is a major contributor to preventable mortality and morbidity. ${ }^{1617}$

\begin{tabular}{llllll}
\hline $\begin{array}{l}\text { Table } 1 \\
\text { Oceania* }\end{array}$ & Prevalence of current tobacco smoking among adults in \\
\hline Country & Year & Age & Male & Female & Total \\
\hline Australia & 2019 & $14+$ & 15.9 & 12.2 & 14.0 \\
\hline New Zealand & $2019 / 20$ & $15+$ & 14.2 & 12.6 & 13.4 \\
Cook Islands & 2016 & $15+$ & 31.8 & 24.0 & 27.8 \\
\hline FSM & 2012 & $12-98$ & 69.1 & 46.9 & 62.4 \\
\hline Fiji & 2011 & $25-64$ & 47.0 & 14.3 & 30.7 \\
\hline Kiribati & 2019 & $15-49$ & 44.9 & 20.4 & - \\
\hline Marshall Islands & 2018 & $18+$ & 43.3 & 4.1 & 22.5 \\
\hline Nauru & 2016 & $18-69$ & 47.4 & 45.3 & 46.3 \\
\hline Niue & 2017 & $15+$ & 24.6 & 11.5 & 17.7 \\
\hline Palau & 2016 & $18-97$ & 30.9 & 9.7 & 20.4 \\
\hline Papua New Guinea & 2018 & $15-49$ & 60.3 & 26.0 & - \\
\hline Samoa & 2019 & $15-49$ & 25.6 & 12.5 & - \\
\hline Solomon Islands & 2015 & $18-69$ & 54.5 & 21.0 & 36.0 \\
\hline Tonga & 2019 & $15-49$ & 52.9 & 16.1 & - \\
\hline Tuvalu & 2015 & $18-69$ & 48.6 & 22.4 & 35.0 \\
\hline Vanuatu & 2011 & $25-64$ & 45.8 & 4.0 & 23.7 \\
\hline Tokelaut & 2015 & $18-69$ & 55.4 & 63.3 & 59.3 \\
\hline
\end{tabular}

- means data not reported or unavailable.

*WHO Global Report on the Tobacco Epidemic, 2021: (https://www.who.int/ publications/i/item/WHO-HEP-HPR-TFI-2021.11.1) NB various measures but used 'current tobacco smoking' or 'current cigarette smoking' according to available data.

†Tokelau is not a signatory to the WHO FCTC/WHO STEPs survey 2005; daily smokers (https://www.google.com/search?q=tokelau+steps+survey\&rlz=1 C1GCEA). FCTC, Framework Convention on Tobacco Control; FSM, Federated States of Micronesia.

\section{TOBACCO CONTROL ACHIEVEMENTS}

Tobacco control achievements in the region have primarily benefited Australia and New Zealand. The decrease in agestandardised smoking prevalence in Oceania (1990-2019) was $16.1 \%$ for the PICTs, compared with $47.5 \%$ for Australia and $40.2 \%$ for New Zealand. ${ }^{18}$

What accounts for such striking differences?

\section{Aotearoa New Zealand}

Strong Māori tobacco control advocacy in Aotearoa New Zealand pioneered discussion of endgame options, such as a private members' bill to end tobacco sales, ${ }^{19}$ and development of the Tupeka Kore ('no tobacco') concept for Aotearoa New Zealand. ${ }^{20}$ In 2010, recommendations from a Māori Affairs Select Committee enquiry ${ }^{21}$ culminated in the commitment to achieving an essentially smoke-free Aotearoa by 2025. New Zealand has been instrumental in gathering evidence and advocating for endgame options. ${ }^{22-24}$ The most recent and potentially boldest action is the New Zealand government's draft plan for achieving the Smokefree 2025 goal released in April 2021. ${ }^{25}$ This sets out a comprehensive plan including world-leading measures $^{26}$ such as greatly reducing the retail availability of smoked tobacco products, phasing out sales through a 'smokefree generation' policy, and removing virtually all the nicotine from cigarettes and rolling tobacco.

\section{Pacific Island Countries and Territories}

At a strategic level, Pacific leaders are committed to tobacco control $^{27}$ with 14 PICT Parties to the FCTC, and all 22 PICTs supporting the Tobacco Free Pacific 2025 goal launched in 2014. ${ }^{28}$ In 2018, the Monitoring Alliance for NCD Action Dashboard $^{29}$ was endorsed at the Pacific Health Ministers Meeting. The Dashboard maps country-level progress against specific NCD policies, prioritising actions and accountably and against specified tobacco control measures, including taxation, smokefree environments, tobacco warnings, advertising and promotion, tobacco licensing, smoking cessation and tobacco industry interference. $^{30}$

A WHO FCTC ${ }^{31}$ report provides evidence of innovation and incremental progress in tobacco control in many PICTs. Most PICTs are implementing FCTC measures, with several being exemplars. These include the Cook Islands which has implemented annual tax increases since 2014, smoke-free environment laws, primary care-delivered cessation support and has trialled SMS-delivered cessation support intervention. Fiji ratified the Protocol to Eliminate Illicit Trade in Tobacco Products (Protocol) and implemented strong taxation, smoke-free environment, packaging and promotion measures. Palau prohibits duty-free tobacco sales, enforces underage sales laws, and hypothecates tobacco tax to NCD prevention and other tobacco control measures including the innovative 'Palau Pledge', which requires visitors to respect smoke-free places and not litter butts. Samoa's 2019 Tobacco Control Amendment ${ }^{32}$ established a multisector tobacco control committee to develop the work plan to promote, among other measures, the Protocol, introduction of tobacco retail licensing, ban tobacco sales by people aged $<15$ years and regulate e-cigarettes. Samoa is a member of the WHO FCTC 2030 project, a prestigious opportunity which provides support to scale up implementation. Papua New Guinea's 2015 policy responses ${ }^{33}$ included a comprehensive package of strategies to reduce the demand for tobacco products, to reduce the cultivation and supply of tobacco and to strengthen international collaboration in tobacco control; providing a basis for 
the review of legislation to control advertising, sales, promotion, graphic pack health warnings, and enforce pricing and taxation measures.

\section{Australia}

Australia is a world leader in tobacco control mass media campaigns, taxation and smoke-free environments. In 2012, Australia implemented the world's first tobacco plain packaging laws, which prohibited branding and promotional text on tobacco packaging and required packs to be 'drab olive-green' with large text and graphic health warnings. ${ }^{34}$ Australia successfully defended these laws against industry challenges and countries acting in the interest of the industry. This success has led to the policy being adopted by 20 other countries ${ }^{35}$ so far, including New Zealand.

There has also been a concerted effort to address smoking among Aboriginal and Torres Strait Islander populations through the Tackling Indigenous Smoking Program, ${ }^{36}$ formerly the Regional Tackling Indigenous Smoking and Healthy Lifestyle Program established in 2010. This was the first significantly resourced, long-term commitment to address Indigenous smoking in Australia with evidence of impact through sizeable reductions in smoking prevalence. ${ }^{37}$

\section{CHALLENGES AND OPPORTUNITIES FOR ACHIEVING SMOKE-FREE STATUS}

Similar tobacco control challenges are faced throughout Oceania, including ongoing tobacco industry interference, as well as distinct country and territory needs and opportunities; reflective of their broader social, environmental, and economic positions and their respective tobacco control journeys.

\section{Aotearoa New Zealand}

New Zealand has an opportunity to lead the world by implementing an innovative Smokefree 2025 Action Plan. ${ }^{26}$ However, fully implementing the proposed policy measures will require ongoing government commitment in the face of anticipated efforts to dilute, delay and derail by the tobacco industry and its allies. Comprehensive tobacco control infrastructure urgently needs to be strengthened including, but not limited to, enhanced mass media and cessation support, and strengthened governance and leadership (especially Māori governance and leadership), compliance monitoring and enforcement, and evaluation and research.

\section{Australia}

Australia has often had bipartisan political support for strong tobacco control measures, but new tobacco control policies in the last decade have been mainly limited to annual tax increases. To offset political complacency, investment is still needed in tobacco control including national mass media campaigns, whole of government, and targeted approaches to address inequities and bolder policy and legislative reform. ${ }^{38} 39$ Reaching the Draft National Preventive Health Strategy's proposed target of less than 5\% smoking prevalence by $2030^{40}$ will require a range of measures such as those outlined in the draft strategy and those being considered in New Zealand. Reducing tobacco supply and availability and regulating the contents of tobacco products have been flagged for implementation over the next 10 years. ${ }^{38} 39$ The Australian tobacco control community must unite and advocate strongly for such measures. However, progress in Australia risks being stalled by a preoccupation with the vaping debate, ${ }^{41}$ which while important, can divert attention from taking the necessary strong evidence-based action on combustible tobacco products.

\section{Pacific Island Countries and Territories}

Tobacco use is a major driver of the burgeoning NCD crisis in the PICTs. ${ }^{42}$ Tobacco control implementation is highly variable in and between countries, with gaps in core FCTC measures and challenges to policy implementation due to under-resourced legislative capacity. Competing priorities, such as COVID-19, climate change, re-emerging infectious diseases and a climate of economic volatility, divert attention from tobacco control. Tobacco industry interference is also widespread ${ }^{43} 44$ with evidence indicating more sophisticated approaches being undertaken by the industry. ${ }^{31}$ Building and retaining a public sector workforce with the technical skills of tobacco control (especially Article 5.3) required to gather and maintain momentum towards full FCTC implementation, especially given competing priorities, remains a widespread challenge.

\section{DISCUSSION}

We have described a number of successes across Oceania; however, few countries have comprehensive tobacco control strategies and there are numerous gaps in FCTC implementation particularly in PICTs. In the mid to long term, the COVID-19 pandemic response (surveillance and cooperation) could bolster tobacco control efforts via clear leadership, reinvigorated bilateral and multilateral arrangements (eg, the Polynesian Health Corridors ${ }^{45}$ ), strengthening the healthcare system and improved public health capacity. Progress in tobacco control is closely aligned with growing Pacific leadership, within and outside government, to continue to invest in a strategic, evidence-based, regional approach to tobacco control.

This work has started with the Oceania Tobacco Control Conferences, the establishment of the Oceania Chapter of SRNT, and more recently a significant effort by Indigenous tobacco control researchers within the Oceania region to reinvigorate the global Indigenous Tobacco Control Network. ${ }^{46}$ However, much of this effort is carried out by the tobacco control sector with limited resources; more can and should be done by governments, particularly the Australian and New Zealand governments, through regional investment to support tobacco control in PICTs. Further, to avoid colonising attitudes to tobacco control development, the focus for this support should be on sustainable capacity and capability building with local leadership and decision-making a priority to reduce tobacco use and improve health outcomes.

\section{CONCLUSION}

Achieving a smoke-free Oceania will have an enormous impact on improving health and well-being. This paper identifies the somewhat sporadic and incremental progress in tobacco control, and the challenge of an active and well-resourced tobacco industry, alongside other impediments to effective tobacco control implementation. To achieve equitable health outcomes across Oceania and full implementation of the FCTC, we need to harness our strengths; bold country and regional smoke-free goals, excellent tobacco control leadership, experience and resources. The collective resources of the region are essential to bolster crosssector technical support that grows and retains country capacity. As depicted in this Māori whakatauki (proverb), everyone has something to offer and by working together we can all flourish. Nāu te rourou, nāku te rourou, ka ora ai te iwi. 
What this paper adds

- This report collates tobacco control data and information across the Oceania region.

- This paper identifies the somewhat sporadic and incremental progress in tobacco control, and the challenge of an active and well-resourced tobacco industry, alongside other impediments to effective tobacco control implementation.

Twitter Judith P McCool @Jude.McCool, Coral E Gartner @CoralGartner and Raglan Maddox@RaglanMaddox

Contributors The lead author HG was invited to submit the article. E-ST, CEG, JPM, $\mathrm{RE}$ and RM contributed to all aspects of the article development including original content and revisions. HG submitted the article.

Funding The authors have not declared a specific grant for this research from any funding agency in the public, commercial or not-for-profit sectors.

Map disclaimer The inclusion of any map (including the depiction of any boundaries therein), or of any geographic or locational reference, does not imply the expression of any opinion whatsoever on the part of BMJ concerning the legal status of any country, territory, jurisdiction or area or of its authorities. Any such expression remains solely that of the relevant source and is not endorsed by BMJ. Maps are provided without any warranty of any kind, either express or implied.

Competing interests None declared.

Patient consent for publication Not required.

Ethics approval This paper was commissioned and reports on high-level strategic public policy.

Provenance and peer review Commissioned; externally peer reviewed.

\section{ORCID iDs}

Heather Gifford http://orcid.org/0000-0003-2874-4434

El-Shadan Tautolo http://orcid.org/0000-0001-8444-6410

Coral E Gartner http://orcid.org/0000-0002-6651-8035

Richard Edwards http://orcid.org/0000-0003-2264-9823

Raglan Maddox http://orcid.org/0000-0002-2770-0686

\section{REFERENCES}

1 Paradies Y. Colonisation, racism and Indigenous health. J Popul Res 2016;33:83-96.

2 Ivers RG. Tobacco addiction and the process of colonisation. Aust N Z J Public Health 2002;26:280-1.

3 WHO Framework Convention on Tobacco Control. Available: https://www.who.int/fctcl text_download/en/ [Accessed Jun 2021].

4 Linhart C, Naseri T, Lin S, et al. Tobacco smoking trends in Samoa over four decades: can continued globalization rectify that which it has wrought? Global Health 2017;13:31.

5 Dobell G. Putting Pacific people in Australia's Pacific policy, 2020. Available: https:// www.aspistrategist.org.au/putting-pacific-people-in-australias-pacific-policy/ [Accessed Jun 2021].

6 Stats NZ. New Zealand's population reflects growing diversity, 2019. Available: https://www.stats.govt.nz/news/new-zealands-population-reflects-growing-diversity [Accessed Jun 2021].

7 State Society and Governance in Melanesia. What does the 2016 census reveal about Pacific Islands communities in Australia? James Batley, 2017. Available: http:// bellschool.anu.edu.au/sites/default/files/publications/attachments/2017-09/ib_2017_ 23_batley_revised_final_0.pdf [Accessed Jun 2021].

8 Australian Parliament. New Zealanders in Australia: a quick guide, 2016. Available: https://www.aph.gov.au/About_Parliament/Parliamentary_Departments/ ParliamentaryLibrary/pubs/rp/rp1617/Quick_Guides/NZAust [Accessed Jun 2021].

9 New Zealand foreign Affairs and trade. Available: https://www.mfat.govt.nz/en/ countries-and-regions/australia-and-pacific/niue/ [Accessed Sep 2021].

10 Edwards R, Hoek J, Wilson N. What does the 2019/20 NZ health survey tell us about progress towards a Smokefree Aotearoa? public health expert. Wellington: University of Otago, 2020. https://healthcentral.nz/what-does-the-2019-20-nz-health-surveytell-us-about-progress-towards-a-smokefree-aotearoa/

11 Australian Institute of Health and Welfare. Tobacco smoking. Canberra: Australian Institute of Health and Welfare, 2020. https://www.aihw.gov.au/reports/australiashealth/tobacco-smoking

12 Australian Institute of Health and Welfare. National drug strategy household survey 2019. drug statistics series No. 32. Phe 270. Canberra AlHW, 2020.
13 Atkinson J, Salmond C, Crampton P. NZDep2018 index of deprivation. interim research report, December 2019. Wellington: Department of Public Health, University of Otago, Wellington, 2019. https://www.otago.ac.nz/wellington/otago730394.pdf

14 Ministry of Health. Annual data explorer 2019/20: new Zealand health survey, 2020a. Available: https://minhealthnz.shinyapps.io/nz-health-survey-2019-20-annual-dataexplorer/_W_6967fcfd/\#!/explore-topics [Accessed 26 Jan 2021].

15 Greenhalgh EM, Scollo MM, Pearce M. Socio-Economic position and disparities in tobacco exposure and use. in Scollo, MM and Winstanley, MH (editors) tobacco in Australia; facts and issues. Melbourne: Cancer Council Victoria, 2019. https://www. tobaccoinaustralia.org.au/chapter-9-disadvantage/9-1-socioeconomic-position-anddisparities-in-toba

16 Thurber KA, Banks E, Joshy G, et al. Tobacco smoking and mortality among Aboriginal and Torres Strait Islander adults in Australia. Int J Epidemiol 2021;50:942-54.

17 Australian Institute of Health and Welfare. Health risk factors among Indigenous Australians. Canberra: Australian Institute of Health and Welfare, 2020. https:// www.aihw.gov.au/reports/australias-health/health-risk-factors-among-indigenousaustralians

18 Reitsma MB, Fullman N, Ng M, et al. Smoking prevalence and attributable disease burden in 195 countries and territories, 1990-2015: a systematic analysis from the global burden of disease study 2015. Lancet 2017;389:1885-906.

19 Ban smoking anywhere, any time, says Maori Party New Zealand herald, 2006. Available: https://www.nzherald.co.nz/nz/ban-smoking-anywhere-any-time-saysmaori-party/2HCRA5IWQHIAUYD4DSBM45JZ6A/ [Accessed Jun 2021].

20 A Smokefree Aotearoa action plan: why this could eliminate smoking disparities for Māori, 2021. Available: https://blogs.otago.ac.nz/pubhealthexpert/a-smokefreeaotearoa-action-plan-why-this-could-eliminate-smoking-disparities-for-maori/ [Accessed Jun 2021].

21 Māori Affairs Committee. Inquiry into the tobacco industry in Aotearoa and the consequences of tobacco use for Māori. Wellington: NZ Government. Public Health Expert. Otago University, 2021. https://www.parliament.nz/en/pb/sc/reports/ document/49DBSCH_SCR4900_1/inquiry-into-the-tobacco-industry-in-aotearoa-andthe-consequences

22 Donny EC, Walker N, Hatsukami D, et al. Reducing the nicotine content of combusted tobacco products sold in New Zealand. Tob Control 2017;26:e37-42.

23 Thomson $\mathrm{G}$, Edwards R, Wilson $\mathrm{N}$, et al. What are the elements of the tobacco endgame? Tob Control 2012;21:293-5.

24 Achieving endgames Lessons from the international endgames comparison project and New Zealand's Smokefree 2025 goal Tobacco Endgame Sweden 2025, 12-13 June 2018, Stockholm Richard Edwards and Louise Thornley ASPIRE 2025, University of Otago, Wellington. Available: https://www.folkhalsomyndigheten.se/contentassets/ fc67eab06cf14313b34ea55566a9ac57/12-06-lessons-international-endgamescomparison-project-new-zealand.pdf [Accessed Jun 2021].

25 New Zealand Government proposes world-leading action plan to achieve Smokefree 2025 goal. Tobacco control Blog. posted on may 5, 2021 by Marita Hefler, Richard Edwards and members of the ASPIRE 2025 research centre. Available: https://blogs. bmj.com/tc/2021/05/05/new-zealand-government-proposes-world-leading-actionplan-to-achieve-smokefree-2025-goal/ [Accessed Jun 2021].

26 Ministry of Health. Proposals for a Smokefree Aotearoa 2025 action plan: discussion document. Wellington: Ministry of Health, 2021. https://www.health.govt.nz/ publication/proposals-smokefree-aotearoa-2025-action-plan

27 Sarfati D, Dyer R, Sam FA-L, et al. Cancer control in the Pacific: big challenges facing small island states. Lancet Oncol 2019;20:e475-92.

28 Tobacco Free Pacific 2025 - Healthy Islands are Tobacco Free Islands. Regional initiative proposal submitted by The Secretariat of the Pacific, 2018. Available: https:// www.forumsec.org/wp-content/uploads/2018/05/Tobacco-Free-Pacific-2025-HealthyIslands-are-Tobacco-Free-Islands.pdf [Accessed Jun 2021].

29 Pacific Ncd roadmap and monitoring alliance for Ncd action (manA): progress update presented by: Dr Si Thu WIN tin (SPC) and DR Wendy Snowdon (who). Available: https://bmcpublichealth.biomedcentral.com/articles/10.1186/s12889-020-08795-2 [Accessed Jun 2021].

30 World Bank. Non-Communicable disease (NCD) roadmap report. Washington, DC: World Bank Group, 2014. http://documents.worldbank.org/curated/en/ 534551468332387599/pdf/893050WPOP13040PUBLICOONCDORoadmap.pdf

31 World Health Organization \& WHO Framework Convention on Tobacco Control. Who FCTC implementation review in Pacific island countries. World Health organization, 2020. Available: https://apps.who.int/iris/handle/10665/337194 [Accessed Jun 2021].

32 Samoa: Strengthening the country's tobacco control act, 2019. Available: https:// untobaccocontrol.org/impldb/samoa-strengthening-the-countrys-tobacco-control-act/ [Accessed Jun 2021].

33 Papua New Guinea National Department of Health. Tobacco control policy 2015, 2015. Available: https://health.gov.pg/pdf/TCP_2015.pdf

34 Tobacco tactics University of Bath plain packaging. Available: https://tobaccotactics. org/wiki/plain-packaging/ [Accessed Jun 2021].

35 Timeline of Events. Plain tobacco packaging in Australia; a timeline of legislative and legal developments. cancer Council. Available: https://www.cancervic.org.au/ plainfacts/timelineandinternationaldevelopments [Accessed Jun 2021].

36 Tackling Indigenous Smoking Program. Available: https://tacklingsmoking.org.au/ [Accessed Jul 2021]. 
37 Maddox R, Thurber KA, Calma T, et al. Deadly news: the downward trend continues in Aboriginal and Torres Strait Islander smoking 2004-2019. Aust N Z J Public Health 2020;44:449-50.

38 Gartner CE, Wright A, Hefler M, et al. It is time for governments to support retailers in the transition to a smoke-free Society. Med J Aust 2021. doi:10.5694/mja2.51312. [Epub ahead of print: 22 Oct 2021].

39 Future of tobacco product regulation in Australia. Authored by Kylie Morphett and coral Gartner, 2021. Available: https://insightplus.mja.com.au/2021/6/future-oftobacco-product-regulation-in-australia/ [Accessed Jun 2021].

40 Department of Health. Draft national preventive health strategy 2021-2030. Canberra: Commonwealth of Australia, 2021. https://consultations.health.gov.au/ national-preventive-health-taskforce/draft-national-preventive-health-strategy/

41 Smoke and mirrors? Experts divide over Australia's e-cigarettes ban. Available: https:// www.theguardian.com/society/2017/aug/28/smoke-and-mirrors-experts-divide-overaustralias-e-cigarettes-ban [Accessed Jun 2021].
42 World Health Organization. Noncommunicable diseases progress monitor 2017. Switzerland:WHO, 2017. http://apps.who.int/iris/bitstream/10665/258940/1/ 9789241513029-eng.pdf

43 Pacific monitoring for Ncd alliance (manA) Dashboard. Available: https:// www.pacificdata.org/dashboard/health-dashboard/tobacco [Accessed 13 Sep 2021].

$44 \mathrm{McCool}$ J, McKenzie J, Lyman A, et al. Supporting Pacific island countries to strengthen their resistance to tobacco industry interference in tobacco control: a case study of Papua New Guinea and Solomon Islands. Int I Environ Res Public Health 2013;10:3424-34.

45 New Zealand Foreign Affairs and Trade. Activity Development: Health Corridors Strengthening Health Systems. Available: https://www.mfat.govt.nz/assets/Aid/IATI/ ACT-0100717.pdf [Accessed Jun 2021].

46 Waa A, Robson B, Gifford $\mathrm{H}$, et al. Foundation for a smoke-free world and healthy Indigenous futures: an oxymoron? Tob Control 2020;29:237-40. 